\title{
Fundamentos inmunológicos de la vacunación
}

DR, HERNAN TABOADA L.*

InTroducción. Es evidente que no basta "inocular" o vacunar a un ser humano para protegerlo de una determinada enfermedad. En este procedimiento deben cumplirse algunos requisitos que pueden resumirse en: cantidad y calidad del antígeno, vía de administración y capacidad de respuesta inmunológica del sujeto. En adelante nos referiremos especialmente a este último aspecto.

INMUNIDAD. Se entiende por inmunidad la capacidad de defensa del organismo vivo frente a los agentes patógenos. Dentro de este concepto se distingue un componente inespecífico y otro específico, los que en general interactúan entre ellos:

\section{1.- Factores inespecificos:}

a) generales o anátomo fisiológicos:

- estado nutritivo

- integridad de piel y mucosas

- hormonales (paratiroides, corticoesteroides)

b) celulares:

- leucocitos (fagocitosis y lisis)

- macrofagos (SRE de bazo y ganglios linfáticos. ...).

c) humorales:

- sistema complemento

- properdina (lisina plasmática)

- lisozima y beta-lisina

- interferón (factor antiviral intracelular)

\section{2.- Factores especificos:}

a) celulares: linfocitos $\mathrm{T}$ (timo-dependiente)

b) humorales: linfocitos $B$ (bursa-dependiente $o$ proveniente de médula ósea).

\footnotetext{
* Servicio de Pediatria Hospital Śtero del Río. Cátedra de Pediatría, Universidad Católica de Chile.
}

- células plasmáticas: inmunoglobinas plasmáticas (IgM e IgG) e inmunoglobulinas de secreción $(\operatorname{Ig} \mathrm{A})$.

Simplificando se puede decir que el sistema defensivo trabaja de la siguiente manera:

EI agente agresor foráneo (antígeno) vence las barteras naturales (piel y mucosas) y penetra al organismo. En el lugar de penetración es fagocitado por los macrofagos del sistema reticuloendotelial local. Esto se hace en el bazo si el agente llega por vía sanguínea o en los ganglios si lo hace por vía linfática. Los macrofagos tienen enzimas líticas que degradan al antígeno. Una fracción de éste es presentada en forma soluble (unida al ácido ribonucleico mensajero o RNA-m) a los linfocitos T, los que tienen la propiedad de reconocer lo propio y de reaccionar inmunologicamente contra lo extrano adquiriendo propiedades quimiotácticas, citotóxicas, de inmovilizar a macrofagos y de transferir esta información a otros linfocitos. De ellos depende la inmunidad celular, la que se expresa primordialmente en la llamada hipersensibilidad retardada (ejemplarizada en la reacción a la tuberculina) y en el rechazo de injertos.

Simultáneamente el antígeno directamente o por medio del linfocito $T$ inmunocompetente transmite su información o "activa" a varios linfocitos $B$ que de este modo se transforman en células hiperbasófilas grandes que proliferan por división para transformarse luego en células plasmáticas, las que a su vez comienzan la formación de inmunoglobulinas específicas.

La fracción macroglobulínica o $\operatorname{IgM}(19, \mathrm{~S})$ al unirse al antígeno activa al sistema completo (C), adquiriendo éste así propiedađes líticas (bacteriolisimas, hemolisinas), y dando también origen a substancias quimiotácticas (atracción de leucocitos) y 
anafilactotóxicas (vasodilatación, aumento de la permeabilidad). El proceso inflamatorio tiene a este nivel una de sus génesis, la que polariza el sistema defensivo hacia el sitio amagado.

Simultáneamente, en forma más icnta y dependiendo cuanti y cualitativamente del antígcno, aparece la inmunoglobulina $\mathrm{G}$ o $\operatorname{IgG}$ (75) que alcanza mayor concentración y duración que IgM y representa la respuesta inmunológica definitiva (secundaria). La vida media de la IgG es de 25 días. La IgG, a diferencia de la fracción IgM, pasa al líquido intersticial y en general no fija complemento a menos que sus moléculas estén muy próximas. Su acción es primordialmente opsónica, estimulando la fagocitosis de las partículas de antígeno a las que se adhiere y acelerando su retiro y destrucción por micro y macrófagos.

Un tercer tipo de inmunoglobulina está representado por la lgA (11S) que es producida por las células plasmáticas sub-epiteliales y destinada a aparecer fundamentalmente en las secreciones: lágrimas, saliva, leche, mucus respiratorio, jugos digestivos, orina. . . La IgA resiste la digestión pepticotríptica (7) y es responsable de la importante protección de las mucosas, especialmente respiratoria y digestiva, a las que confiere una especie de barniz inmunológico (74).

Como se ha podido apreciar, es clara la estrecha interrelación entre los factores inespecíficos y los específicos, formándose una cadena complementaria e interdependiente.

-La respuesta inmunológica primaria (10 a 14 días) se esquematiza en el gráfico $N$ No 1.
-En la respuesta inmunológica secundaria (segundo estimulo y subsiguientes) se acorta significativamente el tiempo de latencia a más o menos 5 días. Esto sc explica por la presencia de péqueña cantidad de anticuerpos que actúan como opsoninas acentuando la fagocitocis y por consiguiente dando un mayor estímulo al sistema. Además ya existen linfocitos sensibilizados (memoria inmunológica) capaces de responder directamente al autígeno lo que determina su proliferación y la aparición más rápida y en mayor cantidad de las inmunoglobulinas. Cuando se alcanza entonces una cantidad importante de inmunoglobulinas ( $\mathrm{M}, \mathrm{G}$ o $\mathrm{A}$ ) éstas neutralizan totalmente al antígeno y se obtiene la inmunidad completa: no se aprecia la respuesta externa del organismo a la introducción del agente patógeno, no hay enfermedad.

Con el tiempo desciende la tasa de anticuerpos, pero se restablece una respuesta inmediata ante la llegada de nuevas dosis del antígeno. Siempre permanece una reserva de linfocitos $\mathrm{T}$ con memoria inmunológica ya que tienen una vida larga sin dividirse (hasta 5 años) (58).

Existen algunas variaciones con respecto a la respuesta inmunológica en relación a las infecciones virales. En este caso las partículas antígenas son tán pequeñas que no pueden ser fagocitadas como tales. En la saugre las plaquetas sirven de vehúculo absorbiendo e incluso fagocitando las partículas virales (21-55-56). Ahora el complejo plaqueta-virus sí puede ser fagocitado. En la respuesta es fundamental la participación del comple-

GRAFICO NQ I RESPUESTA INMUNOLOCICA

MaCR Fago

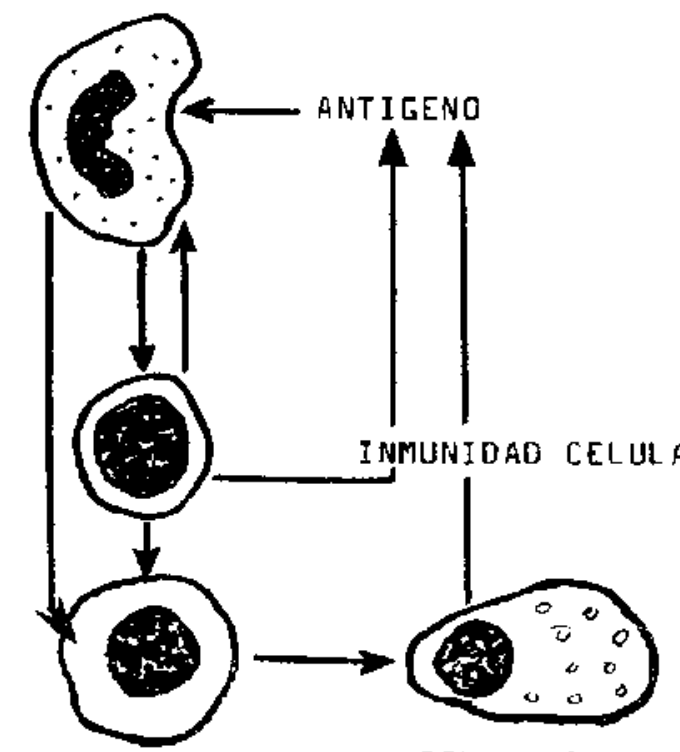

HIDERSENSIBIL ID AD

LINFOCITOT

CELULA PLASARTICA 
mento sobre el complejo virus-anticuerpo, lo que determina la lisis de la membrana viral y luego del microorganismo al ser atacado por otras lisinas (beta-lisina, lisozima).

Se debe recordar además que los virus son intracelulares para su metabolismo y reproducción, dependiendo del sistema biosintético intracelutar (microsomas, ribosomas). A este nivel actúa el interferón, substancia producida por la célula que intercepta el RNA mensajero viral interfiriendo así la información enviada por el virus para la sintesis celular de proteínas indispensables para él y también la posibilidad de sintetizar nuevo RNA o DNA, paralizándose asi la multiplicación viral (52).

\section{Desarrollo del sistema inmunitario:}

El feto se desarrolla en el claustro materno en un aislamiento prácticamente completo del mundo exterior $y$, en condiciones normales, aislado también de su madre. Al comenzar la diferenciación de las células del sistema inmunológico, tienen ellas como primera tarea el aprender a reconocer lo propio y no reaccionar en su contra. Es este un proceso activo denominado tolerancia y que en general se completa durante la primera mitad del embarazo (2-3). Simultáneamente y ya desde sexta semana, se inicia el paso de inmunoglobulina materna a través de la placenta, siendo esto un proceso activo y selectivo ya que pasa sólo la fracción IgG y en consecuencia la protección inmunológica que en ella posee la madre. Los niveles aumentan progresivamente hasta alcinzar su máximo (igual concentración que la materna) entre las semanas 36 y 38 (2).

Esta protección prestada por la madre y lat ausencia de estímulos antigénicos hacen que el niño normal nazea en un estado de virginidad inmunológica. Sin embargo, durante la segunda mitad del embarazo el feto es capaz de respuesta inmunitaria activa cuando es estimulado: aparecen células plasmáticas, IgM y una pequeña proporción de IgG, en casos de lúes, rubéola y toxoplasmosis congénita. (71).

E1 recién nacido normal emerge bacteriológicamente estéril y sin experiencia inmunológica hacia un medio ambiente rico en estímulos antigénicos y en microrganismos patógenos. El éxito con que enfrenta este cambio sugiere que los mecanismos de defensa son suficientes para sobreponerse a la situación (73). Gran parte de esta defensa es inmunidad antiviral y antibacteriana adquirida pasivamente a partir de las IgG maternas. Sin embargo, al estudiar la capacidad de respuesta activa del recién nacido se puede concluir lo siguiente:

-Es capaz de respuesta inmunológica celular (linfocitos T), como lo prueban el viraje tuber- culínico después de la vacuna BCG (33) y el rechazo de injertos, lo que es sin embargo algo más lento que en adulto (28).

-Responde activamente con formación de anticuerpos frente a enterovirus, (26) Coli patógeno, (76) Salmonellas, (73) Pertussis (1), etc... siempre que la tasa de IgG transmitida por la madre sea baja o inexistente. Bajo estas condiciones sc ha observado respuesta al toxoide diftérico administrado antes de los 28 días de vida (18-59). Frente a la salmonella no responde al antígeno somático 0 , pero sí al antígeno flagelar $\mathrm{H}$ con producción de IgM, lo que se prolonga por 20 ó 30 dias, apareciendo la IgG correspondiente en forma tardía y en título bajo (73). Cabe recordar que la respuesta a los gérmenes Gram negativos es predominantemente en base a IgM (35a).

La presencia de IgA en la leche materna proparciona una protección pasiva al tubo digestivo del niño y anula o inhibe en él las respuestas a enterovirus y bacterios patógenos que ilegan por vía enteral.

La protección pasiva dada por la IgG maternas disminuye progresivamente y desaparece casi totalmente entre los 3 y 6 meses de edad (2-35). Se ha demostrado que si el título inicial para el sarampión es muy alto puede persistir hasta los 8, 10 e incluso 12 meses de edad (48).

Durante su primer año de vida deberá el niño afrontar entonces su propia defensa de un modo progresivo tanto en inmunidad celular como a través de la producción de inmunoglobulinas. En el gráfico No 2 se expone cuantitativamente este proceso (35).

TABLA ANEXA

VALORES NORMALES DE INMUNOGLOBULINAS EN ADULTOS

\begin{tabular}{cccc}
\hline $\begin{array}{c}\text { Tipo de in- } \\
\text { munoglobu- } \\
\text { lina }\end{array}$ & $\begin{array}{c}\text { mg. } / 100 \mathrm{ml} \\
\text { suero }\end{array}$ & U/ml. suero & $\begin{array}{c}\text { Vida media } \\
\text { en dias }\end{array}$ \\
\hline $\operatorname{IgG}$ & $1.000(600-1.200)$ & $161 \pm 43$ & 25 \\
$\operatorname{IgA}$ & $90(50-100-400)$ & $177 \pm 66$ & 7 \\
$\operatorname{IgM}$ & $80(50-100)$ & $160 \pm 27$ & 10 \\
\hline
\end{tabular}

A partir del gráfico es posible desprender que:

-En cuanto a IgM e IgA el niño depende en los primeros 3 meses de su capacidad de producirlas. La IgG (60-77) de la madre lo protege contra virus y bacterias Gram positivos y cuando es alimentado con leche materna la IgA de ella le protege de enterovirus y patógenos Gram negativos digestivos. Durante los primeros meses igualmente, y por la baja tasa de IgM (29-69-84) e IgA (74) el niño es vulnerable a Gram negativos $y$ virus respiratorios. 


\section{CONCENTRACION DE INMUNOGLOBUL INAS}

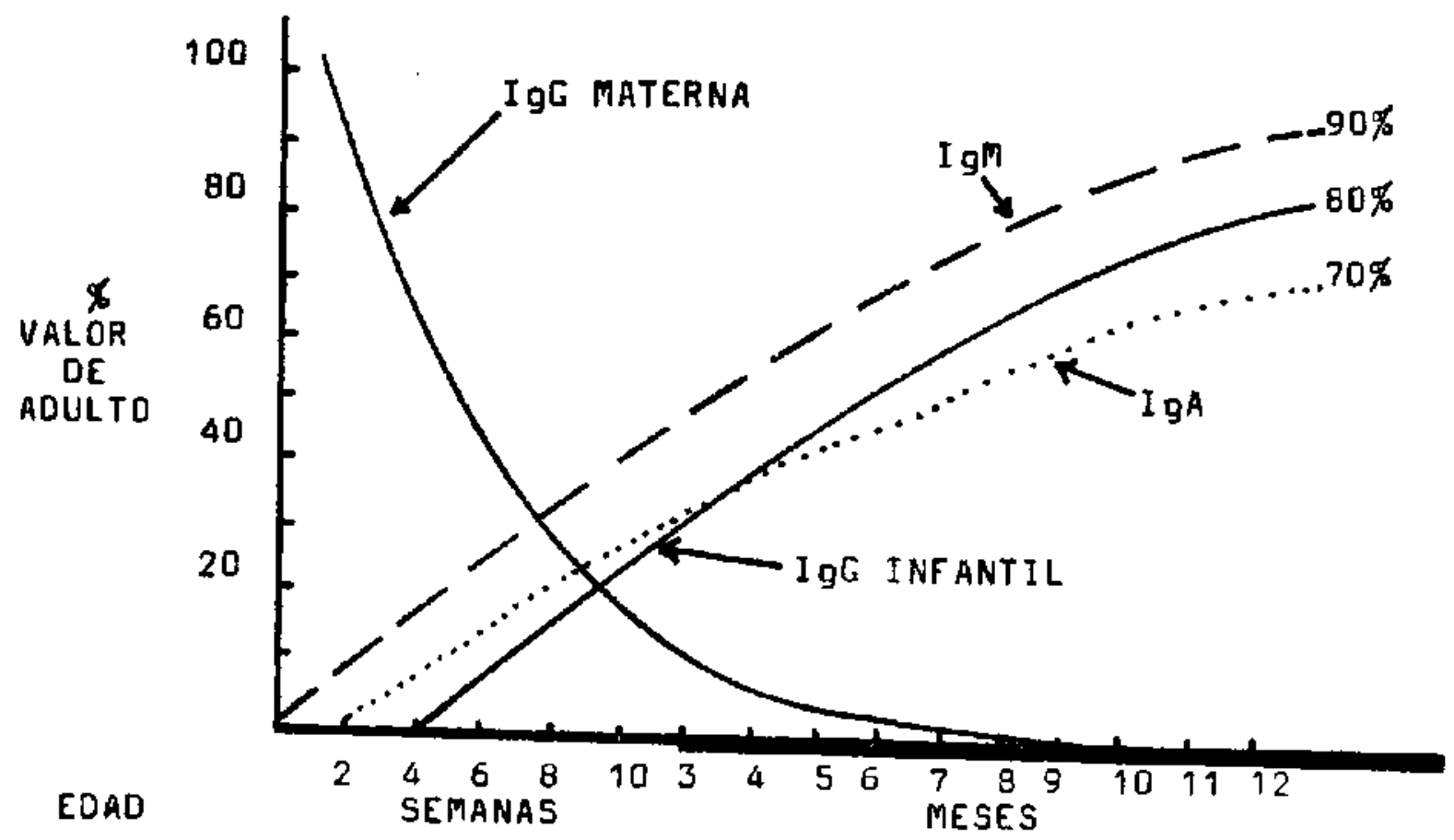

-Entre $\operatorname{los} 2$ y 3 meses se alcanza la tasa más baja de inmunoglobulinas (hipogamaglobulinemia fisiologica), observándose desde entonces un aumento progresivo de las tres fracciones alcanzándose a los 6 meses de edad un $50 \%$ de la tasa del adulto en IgA, un $60 \%$ en IgG y un $70 \%$ en IgM, y al año de vida, $70 \%, 80 \%$ y $90 \%$ respectivamente. En el segundo año de vida se completa la concentración definnitiva de IgM e IgG. La de IgA no lo hace en forma total sino hasta la adolescencia (11-2-35-75). En el Jactante y preescolar los niveles de IgA son bajos y su ascenso es lento, explicando así la mayor tendencia a infecciones respiratorias y digestivas durante los primeros dos o tres años de vida (14).

De todo lo expuesto cabe agregar algunos alcances de importancia:

-En los sindromes de inmunodeficiencia, ya sea celular, humoral o mixta, no procede la intención de aumentar las defensas mediante la vacunación, lo cual incluso involucra riesgos importantes cuando es a gérmenes vivos atenuados: BCG diseminado, generalización de vacuna antivariólica, polionielitis paralítica por vacunacion. (66a).

-Los esquemas de vacunación deben tomar en cuenta, además de las condiciones epiderniológicas locales, el desarrollo inmunológico del ni- ño, especialmente lo que se refiere al bloqueo de 1a respuesta por la presencia de inmunoglobulinas transplacentarias (IgG) y de la leche materna (IgA).

-Debe tenerse presente el respeto de Ios intervalos necesarios entre la primovacunación y revacunaciones con el objeto que larespuesta sea optima: mínimo 4 a 6 semanas para vacunas de un antígeno, 6 a 8 semanas para las vacunas con más de un antígeno y 4 a 6 meses en las dosis de refuerzo posteriores cuando la inmunidad no es duradera (54).

\section{ENFOQUE ESPECIFICO DE LAS DISTINTAS VACUNAS DISPONIBLES}

Vacuna antituberculosis o $B C G$ :

El recién nacido es capaz de responder adccuadamente a la vacuna BCG, como lo prueba el viraje tuberculínico normal a las 3 a 4 semanas (23-42-72-88).

Los lípidos del bacilo de Koch son buenos coadyuvantes inespecíficos de la respuesta inmunológica al estimular la fagocitosis (30-85-86).

Alrededor de los 5 años se ha encontrado un alto porcentaje de niños vacunados con $\mathrm{BCG}$, con 
PPD (-). Por estc motivo se recomienda una dosis de refuerzo alrededor de los 6 años (1.er año de enseñanza básica) y otra en el último año básico.

Vacuna Mixta (Difteria-Pertussis) o mejor Triple (Difteria-Pertussis-Tétano o DPT) * El recién nacido está parcial o totalmente protegido por las IgG maternas en cuanto a difteria se refiere (no así a Pertussis o Tétano). Esto inhibirá una buena respuesta a la vacuna hasta los 3 e incluso 6 meses de vida, siempre que la madre haya tenido contacto con el antígeno correspondiente. La edad óptima para la primera vacuna será entonces a partir del $6^{\circ}$ mes (37). En países de alto riesgo se recomienda la primera dosis a las 6 semanas (5), con 2 dosis de refuerzo (intervalo mínimo de 6 a 8 semanas en vacunas múltiples) No hay protección adecuada hasta después de la segunda dosis. Si se comienza a los 3 meses bastarían 2 dosis, pero debería en este caso administrarse una $3^{\text {a }}$ dosis entre los 9 y 11 meses (intervalo mínimo de 4 a 6 meses), ya que en muchos lactantes la primera dosis puede haber sido parcial o totalmente ineficaz por los motivos expuestos (54). Si se ha comenzado la vacuna después del $6^{\circ}$ mes, bastan 2 dosis que respeten el intervalo mínimo (87), administrándose la tercera dosis entre seis meses y un año después.

Las revacunaciones recomendadas serían: en el segundo año (un año después de la segunda o tercera dosis); en el $5^{\circ}$ año, y entre los 15 y 19 años, esta última sólo con Tétano.

El mayor problema se presenta en relación Coqueluche, que ataca al $90 \%$ de los no vacunados con una cuota alta de mortalidad que se acumula en el primer año de vida (75\% de los fallecimientos y de ellos el $40 \%$ en los primeros 3 meses) (65). Esto se debe como se dijo a que no hay protección adecuada por vía trasplacentaria.

La coqueluche en el primer mes de vida es grave, ya que en el recién nacido depende de la producción de sus propios IgM frente a gérmenes Gram (-). Este problema puede abordarse vacunando adecuadamente a los hermanos mayores y dando protección pasiva con Gama-globulina hiperinmune pertussis al recién nacido y lactante menor contacto de coqueluche (37). Después del $6^{\circ}$ año el riesgo es mínimo, por lo que ya no se recomienda esta vacuna.

La vacuna diftérica conipleta da protección adecuada prolongada (10 años) (65).

La vacuna tétanica es altamente efectiva y da inmunidad de larga duración (5 años seguros) y rápida respuesta a revacunación durante 10 años o más (65). Las reacciones de hipersensibilidad son raras con la $1^{\text {a }}$ dosis, pero se hacen frecuentes

\footnotetext{
- Esta última es la que se emplea en Chile actualmente.
}

si se repiten las dosis en forma exagerada. Por este motivo en el adulto se recomienda revacunaciones cada 10 años.

En caso de heridas se recomienda administrar antitoxina (mejor globulina hiperinmune) sólo a Ios que tienen menos de 2 dosis de vacuna o cuando la herida tenga más de 24 horas sin atención adecuada. Si la vacunación previa es completa, en el tratamiento de las heridas es innecesario dar dosis de toxoide de refuerzo con una frecuencia mayor que de cada 5 años. Lo anterior se resume en el esquema siguiente:

\section{No D OSIS}

\begin{tabular}{lcccc}
$\begin{array}{l}\text { Teianica } \\
\text { Vacuna }\end{array}$ & \multicolumn{2}{c}{$\begin{array}{c}\text { Herida leve } \\
\text { Limpia }\end{array}$} & \multicolumn{2}{c}{ Toda otra herida } \\
\hline & Toxoide & $\begin{array}{c}\text { Glob- } \\
\text { Inmme }\end{array}$ & Toxoide & $\begin{array}{c}\text { Glob- } \\
\text { Inmune }\end{array}$ \\
\hline Incierta & Si & No & Si & Si \\
$0-1$ & Si & No & Si & Si \\
2 & Sî & No & Sí & No* \\
3 o más & No ${ }^{* *}$ & No & No*** & No \\
\hline
\end{tabular}

* Sí, frente a herida de Inás de 24 horas.

* Sí, cuando la fúttima dosis tiene más de 10 años. *** Sí, cuando la última dosis tiene más de 5 años.

Vacuna Antipolio: Se prefiere la vacuna oral con virus atenuado ya que en esta forma se consigue protección local del epitelio intestinal (IgA) y protección general (IgG), obteniéndose una doble barrera defensiva. La vacuna inyectable con virus muerto daba sólo el segundo tipo de protección (general con IgG). Algunos argumentan en favor de esta última vacuna para la segunda dosis ya que la presencia de anticuerpos del tipo IgA en el intestino haría menos efectiva la revacunación oral muy próxima (37).

El recién nacido está protegido del virus polio por las IgG transpacentarias y además por las IgA de la leche materna. Por este motivo se inicia la vacinación a los tres meses, siendo óptimo a los seis. Sin embargo, la administración oral de virus polio vacunal en alta concentración al recién nacido puede vencer tales barreras y llegar a ser efectivo, dando inmunidad local de intestino (IgA) (44).

Debe tenerse presente que la leche materna puede neutralizar totalmente al virus por lo que se recomienda suspender el pecho una vez antes y una vez después de la administración de la vacuna, por lo menos en un perodo óptino de 6 horas en el cual sólo dar agua azucarada (44). Las dosis de vacuna antipolio oral siguen conjuntamente el esquema expuesto para la Mixta o Triple. 


\section{Vacuna Antisarampión:}

Ya se definió que la protección pasiva materna, cuando existe. dura entre 6 y 12 meses. La edad ideal para esta vacuna scrá entonces desde el año de vida en adelante y siempre que no se haya administrado gamaglobulina por to menos hasta 6 semanas antes (53). Sin embargo, en países de alto riesgo como el nuestro, se recomienda vacunar entre los 6 y 10 meses de edad, lo que implica un menor rendimiento en la conversión serológica (sólo $86 \%$ de positividad en la producción de anticuerpos entre los 9 y 11 meses contra $98 \%$ entre los 12 y 14 meses (48). Sería aconsejable entonces en este caso dar una segunda dosis despues del año de vida para proteger adecuadamente a los niños que no respondieron a la primera dosis. La vacuna con virus atenuado da protección prolongada, más de 8 años y quizás para toda la vida, esto último cuando existe contacto ocasional posterior con el virus natural, io que aumenta periódicamente la tasa de anticuerpos protectores.

La vacuna con virus muerto dio en cambio protección mucho más corta y al bajar la tasa de anticuerpos se han descrito dos tipos de reacciones:

-General, que se produce por el contacto con el virus natural como una enfermedad grave con fiebre alta, rash atípico extenso, con comienzo en las extremidades y neumopatía grave. La neumopatía se debería a un desajuste inmunológico con ausencia de $\lg \mathrm{A}$, que protege cl epitelio respiratorio, lo que permite la unión del virus en alta concentración con la IgG neutralizante activándose así el complemento, el cual al fijarse al complejo antígeno-anticuerpo provoca las Jesiones tisulares inflamatorias descritas. (32-66).

-Local: al revacunar con virus a niños previamente vacunados con virus muertos se producc en el sitio de la inyección una extensa reacción de eritema e induración. En esta lesión se ha comprobado la presencia de IgG y complemento (C3) junto al antígeno inoculado, lo que significa una injuria tisular del tipo del fenómeno de Arthus. (13-70).

\section{Vacuna antivariólica:}

El menor riesgo de reacciones adversas (generalización, encefalitis) se ha establecido en el segundo año de vida para la primovacunación. Se recomiendan revacunaciones al entrar y dejar el colegio (a los 5 años y entre los 15 y 19 años) siendo innecesaria una dosis intermedia entre los 8 y 12 años (80). La norma racional del SNS considera sólo una revacunación en el cuarto año básico.

Son contraindicaciones absolutas los sindromes de déficit inmunitario (esto vale para todas las vacunas con virus o bacterias vivas atenuadas: BCG, polio, sarampión, etc.) y son contraindicaciones relativas las dermatosis alérgicas ( (eczema) y la inmadurez inmunológica del primer semestre. En caso de viaje inevitable se puede recurrir a la vacuna diluida.

Durante el embarazo está contraindicada la primovacunación, en cambio la revacunación no tiene riesgo (22).

Las complicaciones (vaccinia) pueden ser tratadas con globulina hiperinmune o con methisazone, derivado éste de thiosemicarbasona con acción sobre el virus variólico (37).

\section{Vacuna antirrubeólica:}

Se producen epidcmias de rubéola cada 6 a 9 años. En la enfermedad natural se multiplica el virus en faringe y sangre una semana antes del rash, permaneciendo en la faringe entre 2 y 3 semanas después y sólo 2 a 3 días en la sangre (riesgo de embriopatía). Los anticuerpos se detectan en el $100 \%$ de los casos poco después del rash, dando el título máximo a los 30 días. Su persistencia es parecida a la del sarampión (47).

La vacuna con virus atenuado (inyectable o por instilación nasal) proporciona seroconversión entre $80 \%$ y $92 \%$ de los casos susceptibles, siendo éstos alrededor del $13 \%$ de los adultos del medio urbano. Con la vacuna no se produce viremia, y si se produce es insignificante, y la tasa de anticuerpos es más baja, de 4 a 8 veces menor, y más tardía que en la enfermedad natural $(22-49)$.

\section{Esquemas de vacunación} antirrubeólica propuestos:

a) Todos los niños de 1 a 12 años y en las mujeres adultas suceptibles, con la corresvondiente vacunación en las nin̄as de 12 años (USA).

b) Una dosis a niñas de 10 a 14 años y en mujeres adultas suceptibles (Inglaterra).

\section{Vacuna antiparotiditica:}

Se ha establecido que el $95 \%$ de los lactantes de 2 meses de edad posee anticuerpos neutralizantes (IgG maternas), bajando a un $70 \%$ a los 5 messes y corcciendo de ellos en su totalidad al año de edad (39). Por esta razón se recomienda la vacuna con virus atenuado a partir del año de edad, con la que se obtiene entre un $88 \%$ y $98 \%$ de seroconversión. De éstos, el $91 \%$ presenta test cutáneo positivo por hipersensibilidad retardada, ln que traduce inmunidad celulac (linfocito $\mathrm{T}(15-41-81)$.

La vacuna sería útil para prevenir las complicaciones más serias de la parotiditis: orquitis con 
esterilidad posterior (82), Jaberintitis con sordera irreversible (50), pancreatitis con secuela de diabetes $(10-25)$ y posiblemente, la fibroelastosis del endocardio, afección congénita grave que se ha relacionado con parotiditis de la embarazada $(31-57)$.

\section{Vacuma antitifica:}

Esta vacuna proporciona protección total o parcial en un $80 \%$ durante un año y en un 50 a $60 \%$ durante 3 años, cuando se administra mediante inyecciones de gérmenes muertos por calor y fenolizados. La protección sería de un $90 \%$ por 3 años cuando son muertos con acetona (79). Cuando no se logra protección total con la vacunación, se obtiene una enfermedad más leve y una escasa incidencia de portadores (67).

No está indicada en menores de 1 año.

Se la prefiere por vía intradérmica.

Es ventajosa la idea de una vacuna con gérmenes vivos atenuados administrados por vía oral, en el sentido de la protección local del intestino (IgA) y general (IgM e IgG), lo que ya se ha discutido en el caso de la vacuna antipolio oral (74). Sin embargo este ideal no se ha podido lograr por no disponerse de una cepa atenuada de virulencia fija.

\section{Vacuna antïnfluenza:}

Esta vacuna tiene en general un bajo rendimiento cuando se administra en forma inyectable con virus muertos. La respuesta favorable es de un 40 a $60 \%$. La inmunidad obtenida, además, es de corta duración incluso después de la enfermedad natural, a lo que hay que agregar la dificultad adicional derivada de las mutaciones periódicas e impredecibles del virus (40).

Con adyuvantes se ha logrado aumentar la respuesta a esta vacuna a títulos 4 a 16 veces siperiores, incluso reduciendo el antígeno 4 veces. Se ha obtenido protección completa por más de 7 meses a influenza 8 con dos dosis separadas por tres semanas (6).

Otro adelanto se ha conseguido con vacuna a virus vivo atenuado en aerosol, con la que se obtuvo un $79 \%$ de protección en comparación con un $27 \%$ de positividad al administrarse por vîa subcutánea. La vacuna en aerosol, forma ideal de vacunación para las enfermedades respiratorias, tiene además la ventaja de inducir protección local en el epitelio respiratorio (IgA) (78).

\section{Otras vacunas para virus respiratorios:}

Son altamente deseables en nuestro país, ya que en él las enfermedades respiratorias $y$ sus complicaciones determinan la primera causa de mortalidad infantil. Se estima que entre un $60 \%$ y $80 \%$ de dichas afecciones respiratorias seria de origen viral (16). Sin embargo, el desarrollo de este tipo de vacunas ha enfrentado serias dificultades técnicas derivadas de algunas de las siguientes características de los agentes patógenos en cuestión:

- Multiplicidad de virus con 85 cepas diferentes.

-Bajo poder antigénico de ellos, especialmente de los virus respiratorio-sincicial (virus $\mathbf{R}$. $\mathbf{S}$. en adelante), para influenza 1 , adeno y rinovirus.

- Situación desfavorable planteada por la necesidad de vacunación precoz del lactante quien responde inmunológicamente en forma débil y además posee anticuerpos maternos bloqueantes.

- Ineficacia de niveles moderados de anticuer pos para prevenir reinfecciones (virus RS y para infuenza 3).

A modo de ejemplo, el virus RS produce en el prematuro una enfermedad respiratoria leve durante 1 a 8 días antes de aparecer el cuadro respiratorio grave de bronquiolitis. La explicación de esto estaría en la ausencia de IgA en la mucosa respiratoria y en la presencia de $\mathbf{I g G} \mathrm{ma}-$ terna, uniéndose a ésta el antigeno en alta concentración y fijando complemento, siendo este procaso el determinante de las lesiones tisulares inflamatorias exageradas. Lo mismo sucedería si se administrara una vacuna a virus RS muerto inyectable. Todo to expuesto además explicaría por qué la bronquiolitis se produce sólo una vez y siempre en lactantes menores (43-45-46).

La solución obvia sería entonces recurrir a la vacuna con virus atenuado que produce inmunidad local (IgA secretoria) y sistémica al virus RS. Desgraciadamente en lactantes pequeños, en donde la vacuna tiene su indicación más precisa, las vacunas ensayadas han producido reacciones que no aconsejan el uso en su estado actual de desarrollo (17). Queda abietto con esto el campo de las vacunas a virus respiratorios atenuados administradas por instilación nasofaríngea o en acrosol con el objeto de cerrar la puerta de entrada a estos microagentes patógenos (62).

Se ha detectado en la secreción nasal anticuerpos de tipo IgA para los siguientes virus: influenza, polio, adenovirus, coxsackie, Echo y rino virus. Existe correlación entre los títulos nasal y sérico de la IgA. Además, después de una infección respiratoria alta, aparecen anticuerpos sistémicos del tipo IgG. La IgA neutralizante determina protección, en tanto se producen reinfecciones con títulos detectables de IgG sérica (7).

De las múltiples familias de virus, hay tres que deterninan la gran mayoría de las infecciones respiratorias inferiores del lactante menor: el virus respiratorio-sincicial y los virus parainfluenza 1 y 
3. Ellos producen afecciones de incidencia anual y estacional coincidentes y en ellos deebieran centrarse los esfuerzos para conseguir las vacunas eficaces que permititían disponer de una acción preventiva programada $(36-51-62)$.

\section{Inmunoterapia e inmunoprofilaxis pasivas}

Los alcances sc referirán fundamentalmente a la administración de inmunoglobulinas, que reemplaza cada vez más a la antigua sueroterapia. Existe actualmente dos tipos de inmunoglobulinas, a saber:

\section{1.- Gammaglobulina comercial corriente:}

Proviene de un pool de plasma de nuchos dadores y contiene alrededor de $15 \mathrm{~g}$. por $100 \mathrm{ml}$. conpredominio de IgG y escasa proporción de IgM e IgA (proporciones similares a las del plasma). La duración de su acción está dada por la vida media de la fracción IgG y en general no va más allá de las 4 a 6 semanas. La IgM e IgA tienen una vida media muy corta y en cuanto a la IgA ya se dijo que debe ser básicamente secretada de modo que su muy bajo nivel sérico no es útil y viene sólo a representar probablemente un rebalse al torrente circulatorio.

La adiministración repetida de esta gamaglobulina a personas inmunocompetentes, puede provocar reacciones de sensibilización o la inactivación de ella por la formación de anticuerpos contra una proteína isogénica (37).

\section{Indicaciones:}

a) Tratamiento de la hipo-o agamaglobulinemia congénita. siempre que afecte principalmente a la producción de $\mathrm{IgG}$. No es efectiva frente al déficit selectivo o concomitante de IgA, aún cuando se puede lograr cierta mejoría. Los sindromes ligados aI déficit de IgA se presentan básicamente como infecciones respiratorias repetidas (déficit de IgA e IgE) (7-14) como infecciones intestinales con sindrome de mala absorción (20-61). Para el primer caso sería útil ja administración frecuente de concentrados de IgA en aerosol y para el segundo, cápsulas digestivas de IgA repetidas a frecuencia por la corta vida de esta inmunoglobulina. Ambos procedinientos no se encuentran aún incorporados a la terapéutica humana.

Los sindromes ligados al déficit de IgG (infecciones severas, sepsis repetidas, etc.) se tratan con gamaglobulina con el objeto de mantener una tasa de IgG superior a los $200 \mathrm{mg}$. por $100 \mathrm{ml}$., lo que se logra en general con $1,8 \mathrm{mbl}$. por $\mathrm{Kg}$. de peso $(0,3 \mathrm{~g}$. por $\mathrm{Kg}$. die peso) como primera dosis y luego, una vez al mes, $0,6 \mathrm{ml}$, por $\mathrm{Kg}$. de peso $(0,1 \mathrm{~g}$. por $\mathrm{Kg}$. de peso) como dosis de mantención. Algunos recomiendan dosis menores a inter- valos más frecuentes, cada semana o cada 15 días (37).

b) Hipogamaglobulinemia adquirida por hipercatabolismo o pérdida de IgG en casos de nefrosis, pénfigo extenso, quemaduras, enteropatía exudativa, linfagiectasia intestinal, etc. El reemplazo de la pérdida es de poca utilidad a menos que se logre corregir el defecto determinante.

c) En la hipogamaglobulinemia transitoria, fisiológica, del prematuro pequeño, en el que se ha apreciado una menor mortalidad con administración de $250 \mathrm{mg}$. de gamaglobulina (38). Sin embargo, se estima que la evidencia es insuficiente para recomendar su uso rutinario.

d) Prevención o atenuación de algunas infecciones virales: de utilidad comprobada ante el sarampión y la hepatitis infecciosa.

-En sarampión: se previene o atenúa la enfermedad según la dosis y según si es administrada durante los 6 primeros días del periodo de incubación o después del sexto. Salvo excepciones justificadas, como enfermedad grave o minusvalía fisiológica, es preferible la atenuación ya que determina inmunidad definitiva. Para la prevención se recomienda una dosis de $0,25 \mathrm{ml}$. $\times \mathrm{Kg}$ peso en los primeros 6 días de incubación; y para la atenuación una dosis de $0,05 \mathrm{ml}$. x kilo de peso, siempre que se administre antes del $6^{\circ}$ día del período de incubación. Después del $6^{\circ}$ día deberá duplicarse esta dosis $(0.1 \mathrm{ml} . / \mathrm{Kg}$.) , pero el resultado es inseguro (9-19). Se puede usar también para la atenuación de las reacciones postvacunales en una dosis de $0,005 \mathrm{ml}$. $x \mathrm{~kg}$. de peso, lo cual implica la administración de la dosis de vacuna sarampión a frasco completo. En la práctica se puede simplificar lo anterior dando:

Atenuación $=250 \mathrm{mg}$. $(2 \mathrm{ml})$.

Prevenciôn: menores de un año $250 \mathrm{mg}$.

$$
\begin{aligned}
& \text { de uno a dos años } 500 \mathrm{mg} \text {. } \\
& \text { (3,5 ml.). } \\
& \text { de } 3 \text { años o más } 750 \mathrm{mg} \text {. } \\
& \text { (5 ml.). }
\end{aligned}
$$

-En hepatitis infecciosa: En relación con el virus $A$, se ha demostrado que con $150 \mathrm{mg}$. ( $5 \mathrm{ml}$.) adultos hay protección durante 6 meses (63). Sin embargo, estudios efectuados en niños de instituciones sugieren una acción atenuante, con modificación de los síntomas, y no prevención (47). Como preventivo en contactos, y especialmenete en embarazadas susceptibles. debe administrarse antes de la exposición o en período precoz de la incubación, en una dosis de $0,02 \mathrm{ml}$. por $\mathrm{kg}$. de peso, o en la práctica, $1 \mathrm{ml}$, bajo los $50 \mathrm{~kg}$. de peso y $2 \mathrm{ml}$. sobre este peso. Los resultados son altamente satisfactorios. Cuando cxiste una exposición o riesgo permanente se recomienda una dosis de 0,12 ml. por $\mathrm{kg}$, de pesco cada seis meses.

Desgraciadamente la gamaglobulina no proporciona protección adecuada en relación al virus $B$ 
(24) o hepatitis por suceso homólogo. En los contaminados con virus $B$, se indica $10 \mathrm{ml}$. por perpersona, con resultados pobres.

En rubéola: Aún hay controversia en cuanto a la utilidad preventiva de ella en el embarazo, lo cual sólo se plantea en las primeras en las 16 semanas de él. Pucde significar una falsa seguridad dicho planteamiento, pues, pese a que la enfermedad materna sea asintomática. el feto puede ser afectado (27-64).

Se recomienda establecer el título previo de anticuerpos y administrar $1.500 \mathrm{mg}$. (10 ml.) de gamaglobulina, cantidad que no modifica significativamente la tasa anterior. Si a las seis semanas no sube el título de anticuerpos se descarta el peligro (49). Si ocurriera un alza significativa debe interrumpirse el embarazo. Se ha planteado el uso de gamaglobulina hiperinmune, que proporcionaría más seguridad, pero evidentemeute, el camino más lógico y seguro es la vacunación preventiva.

2.- Gamaglobulinas especificas o hiperinmunes: Provienen del plasma de convalesciente o de personas recientemente vacunadas con un agente patógeno determinado y tienen, por lo tanto, un alto título de $\operatorname{IgG}$ específica.

-en coqueluche: Se usa gamablobulina hipcrinmune pertussis (hipertussis), que sólo tiene valor preventivo cuando se administra en el período de incubación o catarral precoz. La mayoría de los estudios indican que no tiene valor curativo en el período paroxístico (4).

Se suministra $0,2 \mathrm{cc}$. por $\mathrm{kg}$. de peso o bien $2,5 \mathrm{cc}$. $(1.000 \mathrm{U})$, repartidos en dos dosis separadas por 5 días.

-en tétano: Con 250 a $500 \mathrm{U}$ de inmunogjobulina antitetánica en no vacunados se obtiene protección pasiva durante 4 semanas. Simultáneamente se recomienda dos dosis de toxoide tetánico en sitios distintos y una tercera dosis 4 a 6 semanas đespués (83).

-en viruela: Se puede usar gamaglobulina hiperinmune vacuna o antivaccinia preventivamente o como tratamiento de las complicaciones graves đe Ja vacunación antivariólica. Se puede usar también como profilaxis en contactos de viruela.

Preventivamente junto con la vacuna se adninistra $2 \mathrm{ml}$. (2.000 U). Para el tratamiento de la complicación misma se recomienda 0,12 a $0,24 \mathrm{ml}$. $\mathrm{kg}$. de peso, o en la práctica:

$\begin{array}{ll}\text { menores de } 1 \text { año: } & 2.000 \mathrm{U}(2 \mathrm{ml})) \\ \text { de } 1 \text { a } 6 \text { años: } & 4.000 \mathrm{U}(4 \mathrm{ml}) \\ \text { de } 7 \text { a } 14 \text { años: } & 6.000 \mathrm{U}(6 \mathrm{ml}) \\ \text { mayores de } 15: & 8.000 \mathrm{U}(8 \mathrm{mll})\end{array}$

dosis que se pueden repetir at los dos días si no se aprecia mejoría.

Se puede recurrir también is la N-methilisatinBeta-tiosemicarbasona o methizona (Marboran,
R) en dosis profilácticas de 1,5 a $3 \mathrm{gr}$. dos veces al día durante cuatro días. Esta droga se puede usar en lesiones oculares en forma de solución al $1 \%$ en suero fisiologico (37).

-en parotiditis epidémica: Una dosis de 0,5 $\mathrm{ml}$. por $\mathrm{kg}$. de peso con gamaglobulina hiperinmune respectiva.

-en varicela: Se puede modificar esta enfermedad con inmunoglobulina, pero sólo estaría justificado en prematuros, en enfermos debilitados, con enfermedades malignas, con tratamiento inmunosupresor. Para lograrlo se recomienda una dosis de $0,6 \mathrm{ml}$. por $\mathrm{kg}$. de peso en los 3 primeros dias de exposición (34-89). Se ha demostrado que $2 \mathrm{ml}$. de globulina inmune a zóster previene más que modifica la varicela cuando es administrada dentro de las 72 horas de exposición (12).

-en rabia humana: Se puede usar gamablobulina hiperinmune antirrábica sola o combinada con vacunación en casos de personas mordidas por perros rabiosos. Este producto específico es en general de difícil obtención.

-en enfermedad hemolítica del recién nacido por incompatibilidad RH: siempre que la madre no esté previamente sensibilizada (hemoterapia, transfusiones, abortos, embarazos, etc.) se puede prevenir la apatición de anticuerpos administrando gamaglobulina anti $D$ hiperinmune inmediatamente después del parto o aborto. El parto es el momento de mayor riesgo de paso significativo de sangre de feto a madre. $\mathrm{La}$ inmunoglobulina administrada se fija a estos glóbulos rojos y los elimina rápidanente, antes que estimulen el sistema linfoplasmocitario materno, a lo que se agrega la presencia de una alta tasa de IgG que bloquea la respuesta inmunológica por un mecanismo de homeostasis normal.

Se recomienda una dosis de 250 a 300 microgramos con lo que se proporciona un exceso que cubre transfusiones fetomaternas de hasta $50 \mathrm{ml}$. Con esta medida se lograría un $90 \%$ de efectividad preventiva (68).

\section{Bibliografía}

1.-Adams, J. M. y col: Am. J ,Dis. Child. 74: 10, 1947.

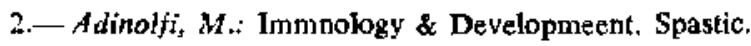
Internat. Med. PubI. London, 1969.

3.-Allison, A. C.: Lancet 2: 1401, 1971.

4.-Balagtos, R. C. y col.: J. Peđiat. 79: 203, 1971.

5.-Barr, M.: Brit. Med. J. 2: 635, 1955.

6.--Beare, A. S.: Lancet 2: 418, 1968.

7.-Bellanti, J. A.: Pediatrics 48: 715, 1971.

8.-Berkovich, S.: Pediatrics 34: 753, 1964.

9.-Black, F. L.: Jama 173: 1183, 1960. 
10.-Blumenthal, H. T.: Arch. Surg. 87: 844, 1968.

11.-Bridges, $R$. A.: J. Lab. \& Clin. Med. 53: 331, 1959.

12.-Brunell, $R$. A.: New Engl. J. Med. 280: 1191, 1969.

13.-Busser, F.: New England J. Med. 277: 250, 1967.

14.-Busser, F, y col:: J. Pediát. 72: 29, 1968.

15.-Buynat. E. B. y col.: Jama 203: 10, 1968.

16.-Chanock, R. M.: Pediatrics 36: 21, 1965.

17.-Chanock, R. M. y cal: Pediatrics 48: 745, 1971.

18.-Christle, A. y col.: Am. J. Dis. Child. 87: 501, 1951.

19,- Cooke, $R$. E.: The Biological Bases of Pediatric Practice P. 629. Blakinston Division, Mac GrawHill, 1968.

20.-Crable, D. A. y col.; Amer. J. Med. 42: 319, 1967.

21.-Danon, D. col.: Virology 9: 719, 1959.

22.-Dixan, C.: Practitioner 207: 433, 1971.

23.-Dorner, B. A.: Lancet 2: 902, 1950.

24.-Drake, M. E.: Jama 152: 690, 1953.

25.-Editorial: Lancet 2: 204, 1971.

26.- Eichenwald, H. F.: Pediatrics 25: 829, 1960.

27.- Forrest, J. M. y col: Arch. Dis. Child, 45: 63, 1970.

28.-Fowlwer R. y col.: Amn. N. V. Acad. Sci. 87: $403,1960$.

29.-Franklin, E. G. y col.: J. Lab. \& Clin. Med. 52: 724, 1958.

30.-Freund, J.: Advances Tuberc. Res. 7: 130, 1956.

31.-Fulgineti, V. A. y col.: Pediatrics 38: 524, 1966.

32.-Fulgineti, V. A.: Jama 202: 1075, 1967.

33,- Gaisford, W.: Brit. Méd. J. 2: 1164, 1955.

34,-Cellis, S. S, Kagan, B. M.: Current Pediatric-Therapy, p. 861, W. B. Saunders Co. Philadelphia, 1970.

35.-Gitlin, D.: Immunological Principles and theeir significance in Pediatrics. Cap. 14, p. 500 de Barnett H. L. Pediatrics 14th Ed. Appleton CenturyCrofts-New York. 1968.

35a.-Gitin, D. y col.: Pediatrics 31: 197, 1963.

36.-Giozen, N. P. y col: J. Pediat. 78: 397, 1971.

37.-Gray, J. A.: Practitioner 206: 494, 1971.

38.-Hobbes, J. R. y col.: Lancet 1: 757, 1967.

39.-Hodes, D. y col.: Pediatrics 45: 99, 1970.

40.-Bolland, W. W.: Practitiones 206: 472, 1971.

41.-Hovowtz, S. D. y col.: Pediatrics. 45: 77, 1970.

42.- lvonside, A. G. Practitiones 206: 488, 1971.

43.-Kapikian, A. Z. y col.: Am. J. Epid. 89: 405 , 1969.

44.-Katz, M. y col.: J. Pediat. 73: 267, 1968.

45.-Kim, H. W. y col.: Am. J. Epid, 89: 422, 1969.

46.-Kim, H. W. y col.: Pediatrics 48: 745, 1971.

47.-Krugman, S.: New, Engl. J. Med. 269: 195, 1963.
48.-Lambert, H. P.: Practitioner 206: 467, 1971.

49.- Lindsay, J. R, y col.: And. Otology 69: 918, 1960.

50.-Maletzky A. J. y col.: J. Pediat. 78: 407, 1971.

51._Marcus, P. I. y col.: Virology 30: 502, 1966.

52.-Measles Vaccines Comittee. Third Report: Practitioner 206: 458, 197 l.

53.- Miller, L. M.: Practitioner 208: 451, 1971.

54.--Movat, H. Z. y col.: Exp. Biol, \& Med. 120: 232, 1965.

56.-Nahnias, A. J. y col.: New, Engl. J. Med. 275: 1448, 1966.

57.-Norman, A. y col.: Nature 147: 745, 1965.

58.- Osborn, J. I. $y$ col.: Pediatrics 9: 736, 1952.

59.- Osbom, J. J. y col.: Pediatrics 10: 328, 1952.

60.-Penny, R. y col.: J. Pediat. 78: 512, 1971.

61._Plotkin, S. A.: Pediatric Clinics N. A. 15: 447, 1968.

62,-- Pollock, T. M. Lancet 1: 281, 1969.

63.-Pollock, T. M.: Brit. Med. Bull. 85: 202, 1969.

64.- Public Health Service Advisory Comittes: Ann. Intern. Med. 76: 289, 1972.

65.-Rawh, I. W.: Am. J. Dis. Child, 109: 232, 1965.

66a.-Riker, J. B. y col. Peediatrics 48: 923, 1971.

66.-Russel, F. M. y col.: Lancet 1: 423, 1968.

67.- Shneider, J.: Comunicación peresonal Soc. Chilena Obs. y Gineol. Mayo 1972.

68.--Schreidengger, J. y col.: Etude Neo-Natales 4: 125, 1957.

69.-Scott, T. J.: J. Med. 277: 248, 1967.

70.-Silvestein, A. M.: Nature 194: 196, 1962.

71.-Smith, M. D.: Pediatrics 32; 444, 1963.

72.-Smith, R. T. y col.: Pediatries 33: 1-63, 1964.

73,-Smith, R. T.: Peediatrics 43: 317, 1969.

74.-Soerensen, R.: Pediatría 14: 15, 1971.

75.-Stalberg C. S.: J. Immunol. 76: 281, 1956.

76.-Valquist, B.: Advances Pediat. 10: 305, 1958.

77.-Waldman, R. H. y col.: Jama 207: 520, 1969.

78.-Walker, J. H.: Practitioner 206: 478, 1971.

79.-Warin, J. F.: Practitioner 206: 483, 1971.

80.-Welbel, R. E. New Engl. J. Med. 276: 285, 1967.

81.-Werner, C. A.: Ann. Intern. Med. 32: 1.066, 1950.

82.-Wesler, S. J.: Jama 207: 123, 1969.

83.-West, C. D. y col.: J. Clin. Invest. 45: 2054, 1962.

84.-White, R. G. y col.: Immunology 1: 54, 1958.

85,-White, R. G. y col.: Immunology 7: 158, 1964.

86.-Wilkins, J. J. y col.: J. Pediat. 79: 197, 1971.

87.-World Health Organization: Tech Rep. Serie No 290, 1964.

88. - Word Health Org. Teach. Rep. 1970. 